\title{
Images of High Density Resistivity Method in Leakage Detecting of the Watertight Screen at Gushan Open-pit Mine
}

\author{
HUANG Wusheng ${ }^{1, a}$, CAI Sijing ${ }^{1, b}$, WANG Wenxiao ${ }^{2, c}$ \\ ${ }^{1}$ Department of Resources Engineering, University of Science and Technology Beijing, Beijing \\ 100083, China \\ ${ }^{2}$ Gushan Mining Company, Ma-steel Group Ltd., Anhui 243184, China \\ ahws82@126.com, bsjcai@ustb.edu.cn, cwang1792@sina.com
}

Keywords: Images of high density resistivity method; leakage detection; watertight screen; Gushan open-pit mine.

\begin{abstract}
High density resistivity method is convenient to be used for explaining the prospected images with efficient information. In the paper, this method was used to detect the quality of watertight screen in the north slope of Gushan open-pit mine. By through inversion, analysis, explanation and speculation, the obtained results showed that the watertight screen was effective in anti-seepage, which provided technical support for the safety of slope extension at Gushan open-pit mine.
\end{abstract}

\section{Introduction}

The Gushan open-pit iron mine locates at a hilly field of the Dangtu county, Anhui province, China, and occupies an area of about $1.2 \mathrm{~km} 2$ with a shape of ellipse. Overburden of the mine is the Quaternary system soil, and after more than 50 years mining operation, the mining line has been down from original $48 \mathrm{~m}$ to now $-36 \mathrm{~m}$. For the north slope of the mine, as there is a river passing nearby, the upper part is sandy soil with rich ground water, and the lower part is sandy gravel with pressurized ground water. In order to mining orebody section below the north slope, a watertight screen was designed and built up, which was about $900 \mathrm{~m}$ in length and $40 \mathrm{~m}$ in depth, as shown in Fig.1. Several ways were used to judge or detect the quality of the watertight screen, including the high density resistivity method[1].

\section{High density resistivity method}

Advantages of using high density resistivity method are: (1) arrangement of detecting electrodes could be finished at one time, and during detecting without any changing or re-arranging; (2) several layouts of the electrodes could be designed, and a large number of electronic images about ground structures could be detected; (3) detecting data can be automatically collected and stored; (4) detecting data can be analyzed in field, or off-line treated later, and tables or figures can be generated; (5) detecting results could be explained quite easily[2,3]. 


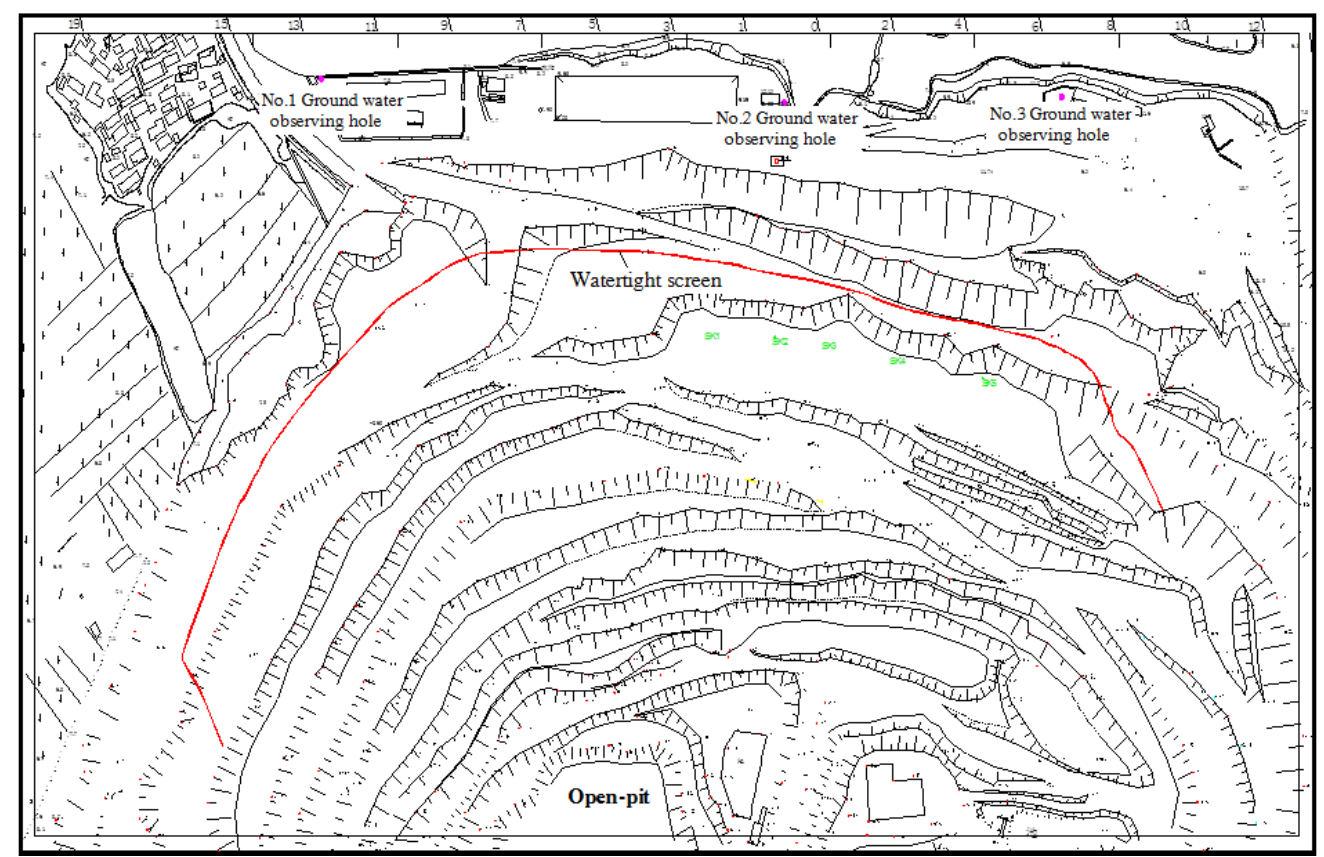

Fig.1 A watertight screen built up at the north slope of Gushan open-pit mine

To carry out the research work of leakage detection of watertight screen in the Gushan open-pit mine, a device called SuperStingR8 Resistivity Imaging System made by the AGI Corporation in USA was used, which includes a main controller, 60 electrodes, a software for 2D and 3D detecting image analysis, as shown in Fig.2.

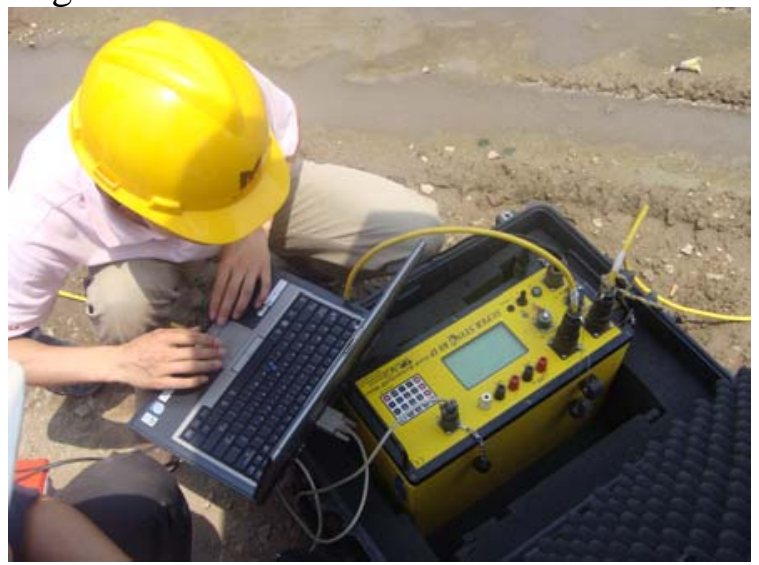

Fig.2 Photo shown main controller of the System in using

\section{Field detecting}

Based on the exploration data, north slope strata of the open-pit are made up with 7 layers of various soil, sand, and gravel. For field detection of high density resistivity method, 4 detecting lines were arranged, where the No.2 detecting line was just followed the watertight screen axes, and No.1 and No.3 lines were at both sides of the watertight screen and parallel to the watertight screen axes, while No.4 line was perpendicular to the watertight screen axes.

During detection, if ground resistance of an inserted electrode was over 2000 ohms, then in order to reduce the resistance to meet the detection requirement, about half a litre of alkaline water was poured on the ground where electrode inserted[4].

Parameters of those 4 detecting lines are listed in Table 1.

Table 1 Parameters of the four detecting lines

\begin{tabular}{c|c|c|c|c}
\hline $\begin{array}{c}\text { Detecting } \\
\text { line }\end{array}$ & $\begin{array}{c}\text { Data } \\
\text { record }\end{array}$ & $\begin{array}{c}\text { Detection } \\
\text { way }\end{array}$ & $\begin{array}{c}\text { Number of } \\
\text { electrodes }\end{array}$ & $\begin{array}{c}\text { Distance of two } \\
\text { Electrodes [m] }\end{array}$ \\
\hline \multirow{2}{*}{ No.1 } & GSL1W & Wenner & \multirow{2}{*}{52} & 5 \\
\cline { 2 - 3 } & GSL1S & Schlumb & 5 & 5 \\
\hline
\end{tabular}




\begin{tabular}{c|c|c|c|c}
\hline & GSL1D & Dip-dip & & \\
\hline \multirow{2}{*}{ No.2 } & GSL2D & Dip-dip & \multirow{2}{*}{60} & \multirow{2}{*}{5} \\
\cline { 2 - 3 } & GSL2S & Schlumb & \multirow{2}{*}{58} & 5 \\
\hline \multirow{2}{*}{ No.3 } & GSL3D & Dip-dip & \multirow{2}{*}{58} & At level, 4 \\
\cline { 2 - 3 } & GSL3S & Schlumb & & Ach \\
\hline \multirow{2}{*}{ No.4 } & GSZD & Dip-dip & \multirow{2}{*}{54} & At slope, 5 \\
\cline { 2 - 3 } & GSZS & Schlumb & & \\
\hline
\end{tabular}

\section{Analysis of inversed images}

During analysis, data iteration method was used. By comparison, the Schlumb detecting data had a more comprehensive result, hence, herein only the Schlumb results were presented.

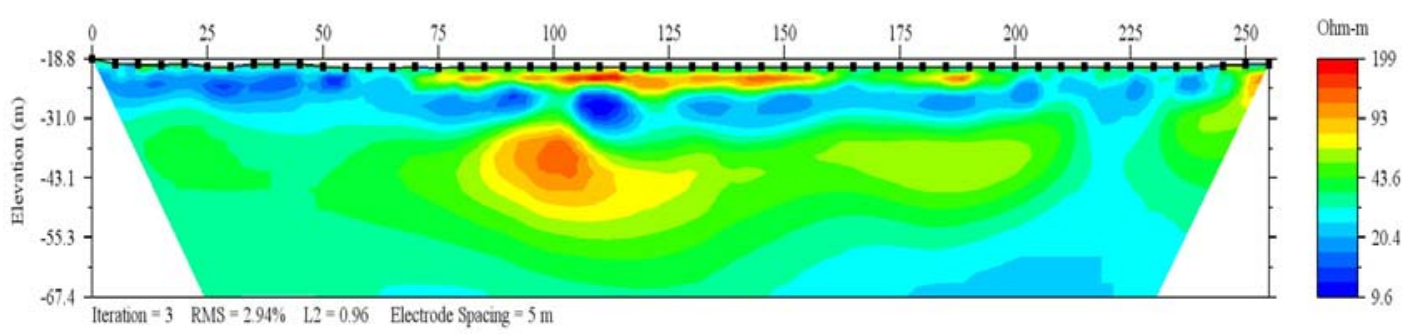

Fig.3 Inversed section image of No.1 detecting line

Fig. 3 is inversed section resistivity image of the No.1 detecting line. From the $0 \mathrm{~m}$ to $70 \mathrm{~m}$ and at elevation of $-19 m$ to $-37 m$, and also from $70 m$ to $200 m$ at elevation of $-24 m$ to $-32 m$, there are two uneven layers of low resistivity, i.e., the blue color area, which were expected to be water-rich layers. Around $100 \mathrm{~m}$ at elevation of $-32 \mathrm{~m}$ to $-67 \mathrm{~m}$, there is a high resistivity center, which was expected to be a small cave.

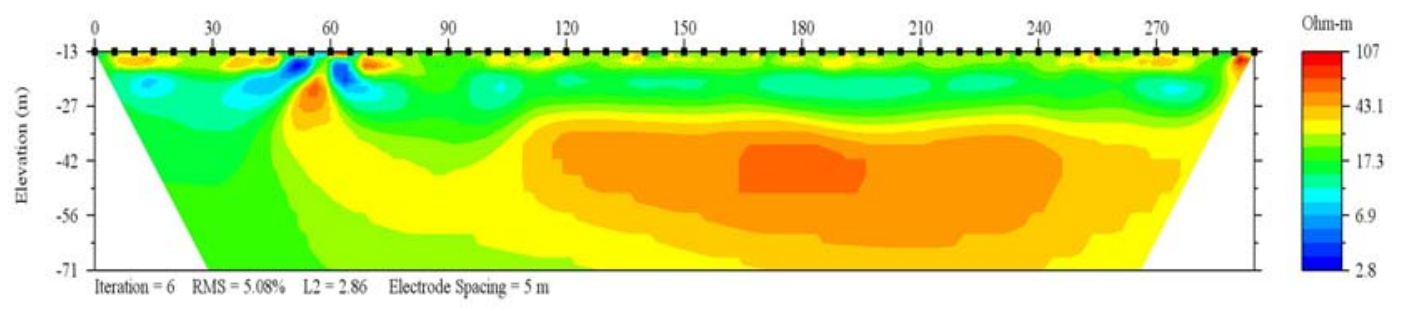

Fig.4 Inversed section image of No.2 detecting line

Fig. 4 is inversed section resistivity image of the No.2 detecting line. From $45 \mathrm{~m}$ to the line end at elevation of $-27 \mathrm{~m}$ down to $-71 \mathrm{~m}$, there is a layer of high resistivity, which was expected the built watertight screen. And around $60 \mathrm{~m}$ there is an uneven layer of low resistivity, which was expected a weak part of the watertight screen.

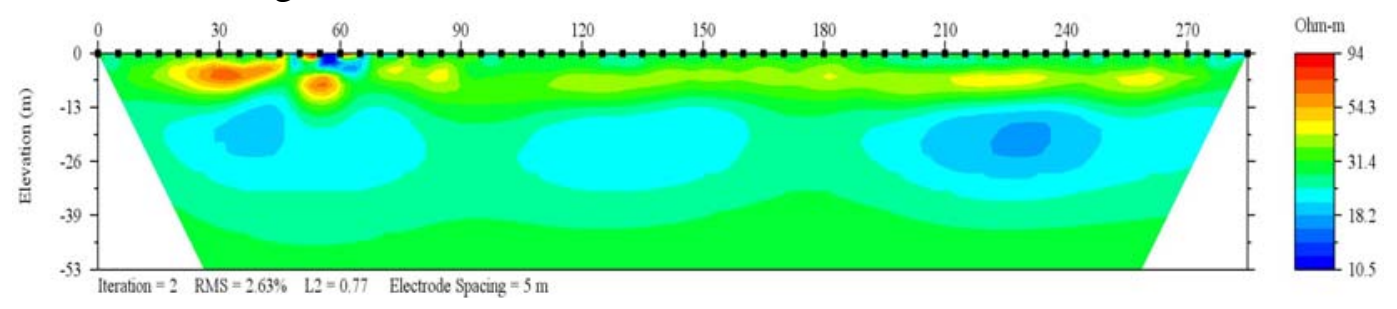

Fig.5 Inversed section image of No.3 detecting line

Fig. 5 is inversed section resistivity image of the No.3 detecting line. From the starting point to the end point at elevation of $-13 \mathrm{~m}$ to $-40 \mathrm{~m}$, there is an uneven layer of low resistivity, which was expected a water-rich layer. 


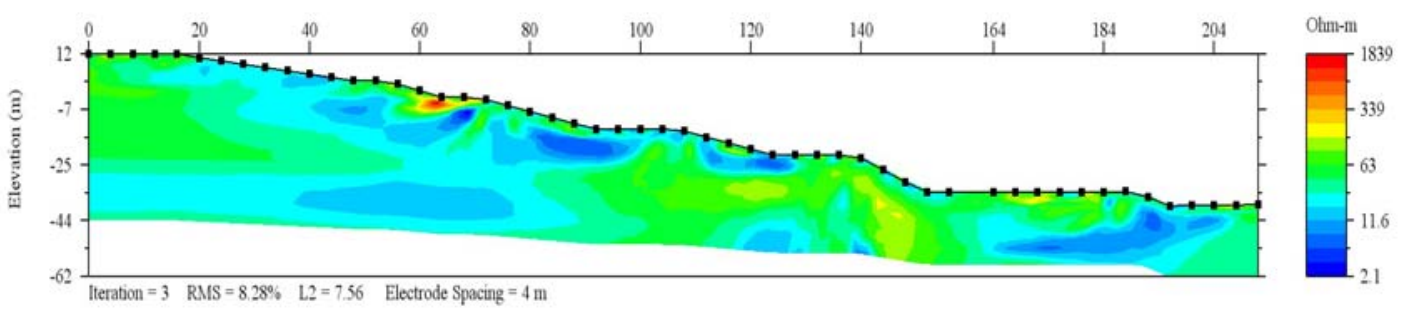

Fig.6 Inversed section image of No.4 detecting line

Fig. 6 is inversed section resistivity image of the No.4 detecting line. From 100m to $150 \mathrm{~m}$ there is area of high resistivity, where was expected just the section position of the watertight screen.

\section{Summary}

After the watertight screen building up two months, mining operation started at the north slope of the open-pit mine[5]. The north slope was safe with little of leaking water, which has proved the success of setting up watertight screen, and also proved the detecting accuracy of high density resistivity method.

\section{References}

[1] S. Jiang, G. Zhu, \& et al, Study on deformation of designed watertight screen in north slope of Gushan mine, Journal of University Geology, 12(2)(2006) 282-284.

[2] R. E. Grilnm, G. R. Olhoeft, K. Mckinley, \& et al, Nonlinear complex-resistivity survey for DNAPL at the Savanah River site A-014 outfall, Journal of Environmental \& Engineering Geophysics, 10(4)(2005) 351-364.

[3] J. Dong, P. Zhai, Z. Zhang, Y. Mou, Application of high density resistivity method in detection of base water body in coal mine working face, Scientific Technology \& Engineering, 16(6)(2008)1550-1552.

[4] L. Zhang, H. Liu, C. Li, Experiment on ground resistance in high-density electrical measurement, Progress in Exploration Geophysics, 33(3)(2010) 179-183.

[5] P. Deng, Z. Wang, Practice of mining under the pressure water of Quaternary System layer in Gushan open-pit mine, Metal Mining, 426(2011) 26-29. 